\title{
Intention to provide tobacco cessation counseling among Indonesian dental students and association with the theory of planned behavior
}

\author{
Diah Ayu Maharani ${ }^{1 *}$, Kiarra Vashti Nadira ${ }^{1}$, Febriana Setiawati ${ }^{1}$ and Maha El Tantawi ${ }^{2}$
}

\begin{abstract}
Background: Use of tobacco is a serious public health problem in Indonesia that requires a multidisciplinary approach by healthcare providers to address it. The study assessed the intentions of undergraduate students in dental schools to provide tobacco cessation counseling (TCC) and their association with the constructs of the theory of planned behavior (TPB).

Methods: A cross sectional study was conducted in October 2019 using an electronic survey for dental students in Indonesian dental schools $(n=30)$. The survey assessed schools and students' characteristics and eleven statements assessed their perspectives toward TCC based on the TPB using a 5-point Likert scale. Principal component analysis (PCA) was used to identify components within the items of perspective. Multilevel linear regression analysis was used to assess the association between intention to provide TCC and the constructs of the TPB as identified in the perspectives' items using TPB controlling for confounders.
\end{abstract}

Results: About 1288 students participated from 30 dental schools, $83.3 \%$ females with mean age $=21.5$ years with average intention to provide TCC $=4.3$ out of 5 . They had above average positive attitude about provision of TCC being the dentist's role (mean $=3.8$ out of 5). PCA identified two components: confidence in their own abilities and perception of favorable environment with average scores $=3.2$ and 2.7 out of 5 . Intention to provide TCC was significantly associated with more positive attitude recognizing TCC as a dentist's role $(B=0.10, P<0.0001)$, greater confidence in skills to provide TCC $(B=0.17, P<0.0001)$ and less perception of favorable environment supportive off providing TCC $(B=-0.20, P<0.0001)$.

Conclusions: Indonesian dental students' intention to provide TCC can be explained by the constructs of the TPB. Development of dental curricula promoting professional responsibility toward TCC should be given attention. Improving students' attitude and confidence potentially may support their patients' efforts to quit smoking.

Keywords: Dental education, Tobacco use cessation, Indonesia

*Correspondence: diah.ayu64@ui.ac.id

${ }^{1}$ Department of Preventive and Public Health Dentistry, Faculty

of Dentistry, Universitas Indonesia, Jalan Salemba No. 4, Jakarta 10430,

Indonesia

Full list of author information is available at the end of the article

\section{Background}

Smoking was the second largest risk factor for premature death and disability in the world with $20.2 \%$ of the population reported to be smoking $[1,2]$. In countries with a medium to low sociodemographic index and below, there was an increase in disease burden due to smoking [3]. Indonesia has one of the highest smoking 
prevalence in the world. Higher prevalence of smoking is seen in people living in poverty, thereby increasing their vulnerability. On average, Indonesian smokers spend $11 \%$ of their income on tobacco which further burdens families [4]. Also, 33.8\% of the population are active smokers, $65 \%$ of males are current smokers [5] and $79 \%$ of children younger than 15 years of age are affected by passive smoking [6]. The deaths caused by smoking in Indonesia account for $14.7 \%$ of total deaths, mostly from cardiovascular disease [7]. Among adolescents under 15 years of age who smoke, 8 out of 10 tried to quit but were unsuccessful due to the addictive effects of nicotine in cigarettes [8]. Smoking increases the risk of cancers $[9,10]$ including those of oral tissues $[11,12]$. In addition, the coaggregation of Streptococcus mutans is higher in active smokers increasing their caries risk [13]. Smoking also results in localized inflammation of periodontal tissues [14, 15].

Health professionals are required to assess cigarette use and to provide counselling for patients to stop smoking [16]. Patients are more likely to quit smoking if health professionals encourage them to do so and help connect them with pharmacotherapy to support stopping efforts [17, 18]. However, in Indonesia, only $34.6 \%$ of smokers reported ever receiving a suggestion to stop smoking by a health professional and only $40.5 \%$ were asked about their smoking history [19]. Dentists can play a role in assessing smoking status and helping patients quit smoking [17] because of dentists' direct and regular contact with their patients. Dentists are also the first health professional to see the effects of smoking in the oral cavity. Thus, dentists are in an ideal position to reinforce anti-smoking messages and motivate and support smokers who want to quit smoking [20]. Available evidence suggested that chairside behavioral interventions for tobacco cessation conducted by dentists may increase tobacco abstinence rates [21].

Patients' awareness that dentist may be a smoking cessation resource, and dentists' confidence in their knowledge and skills to providing smoking cessation services may help patients quit smoking and improve their oral health [22]. Adequate modifications in the dental education curriculum was recommended to improving dentist's involvement in smoking cessation [23]. Education and are needed for dentists to develop their knowledge and abilities $[17,19]$ and foster positive attitudes toward tobacco cessation counseling (TCC) [24-26]. Most dental students are aware that TCC is within the scope of dentist services. However, lack of patients' motivation is the most important factor hindering TCC. The education period is considered the optimum time to train students to give TCC before entering the workforce $[27,28]$.
The theory of planned behavior (TPB) posits that a specific behavior - such as providing TCC- is predicted by the intention to engage in this behavior. Intention, in turn, is related to the attitude toward this behavior, the perceived control over this behavior and the prevailing norms in the surrounding environment toward this behavior. The TPB was previously used to explain dentists' intention to engage in several behaviors such as managing drug users [29], reporting suspected violence against patients [30], managing HIV- positive patients [31] and adopting preventive precautions against COVID-19 [32]. The aim of this study was to assess Indonesian dental students' intention to provide TCC and whether this intention can be explained by the TPB. The null hypothesis was that there was no association between intention to provide TCC and the constructs of the TPB.

\section{Methods}

In this cross-sectional study, all dental student in Indonesia (estimated number $=6132$ ) in 30 dental schools were invited to participate in a survey in October 2019. The study protocol was approved by the Research Ethics Committee, Faculty of Dentistry, Universitas Indonesia (\#66/Ethical Approval/FKGUI/VIII/2019). Written informed consent was obtained from all participants. Students were eligible to participate if they were enrolled in a Bachelor of Dentistry program in an Indonesian dental school anywhere in the country and whether the school was public or private. Students in any program level were included provided they consented to participate.

A questionnaire was developed based on previous research [28] with modifications to fit the study purpose. The questionnaire consisted of two sections. Section 1 assessed dental schools and students attributes: whether the school was in Java or other regions, whether it was public or private, student's age in years at last birthday, gender (male or female), program level (preclinical or clinical) and smoking status (never, former and current). Section 2 included 11 statements assessing students' perspectives regarding TCC including attitude, perceived confidence to provide TCC and support to TCC based on patients' acceptability and dental clinic setup. These items corresponded to the constructs of the TPB: attitude toward behavior, perceived control and subjective norms [33]. Each of the 11 items was scored on a 5-point Likert scale ranging from Strongly Agree (code 1), Agree, Neutral, Disagree, Strongly Disagree (code 5).

The English questionnaire was translated to Bahasa Indonesia in accordance with the cross-cultural adaptation process guidelines [34]. Face validity of the questionnaire was assessed by 5 students to ensure clarity and wording comprehensiveness. The questionnaire 
was uploaded to Google Forms. A link to the electronic questionnaire was sent to the coordinators of the dental school in each of the 30 universities in Indonesia. The coordinators distributed the links to the dental students in their respective schools. The completion of the survey was unsupervised and non-obligatory. To ensure that the questionnaire was filled by students, they needed to enter their national student's ID number. The survey period was limited to 1 month.

\section{Data analysis}

IBM SPSS Statistics for Windows, version 23.0 (SPSS Inc., Chicago, USA) was used for data analysis. Descriptive statistics were calculated as frequencies and percentages or means and standard deviations. Principal component analysis (PCA) was used to identify the main components present within the items representing students' perspectives regarding TCC after the calculation of Kaiser-Meyer-Olkin (KMO) measure of sampling adequacy and the $p$ value of Bartlett's test of sphericity to assess the suitability of data to PCA. Varimax rotation with Kaiser normalization was used. Loadings $<0.35$ were suppressed to facilitate interpretations of loadings. Cronbach alpha was used to assess the internal consistency of the items forming the components identified by PCA. A score was calculated for the items forming each component by averaging the scores of all included items creating scores that ranged from 1 (strongly agree: least negative) to 5 (strongly disagree: most negative). Multilevel linear regression analysis was used based on the Generalized Linear Mixed models procedures in SPSS to account for the clustering of students within dental schools where students represented level 1 and schools represented level 2 . The dependent variable was intention to deliver TCC on a score from 1 to 5 with scores reversed so that score 5 indicated the greatest intention. The fixed effect dependent factors were dental school attributes (region and type of school) and student's attributes (age, gender, program level and smoking status) in addition to items as classified by PCA. Dental schools were entered as random effect variables. Regression coefficient, 95\% confidence intervals (CI) and $p$ values were calculated. Significance was set at $5 \%$.

\section{Results}

The survey was sent to 6132 and 1288 students responded (response rate $=21 \%$ ). Descriptive data of the Indonesian dental students participating this study are shown in Table 1 . Half the participants were from Java (50.3\%). Most of them were from public dental schools (64.5\%), in the clinical level of the program (52.8\%) and females $(83.3 \%)$ with mean age $=21.5$ years. The majority never smoked (90.6\%) and on average, they expressed an

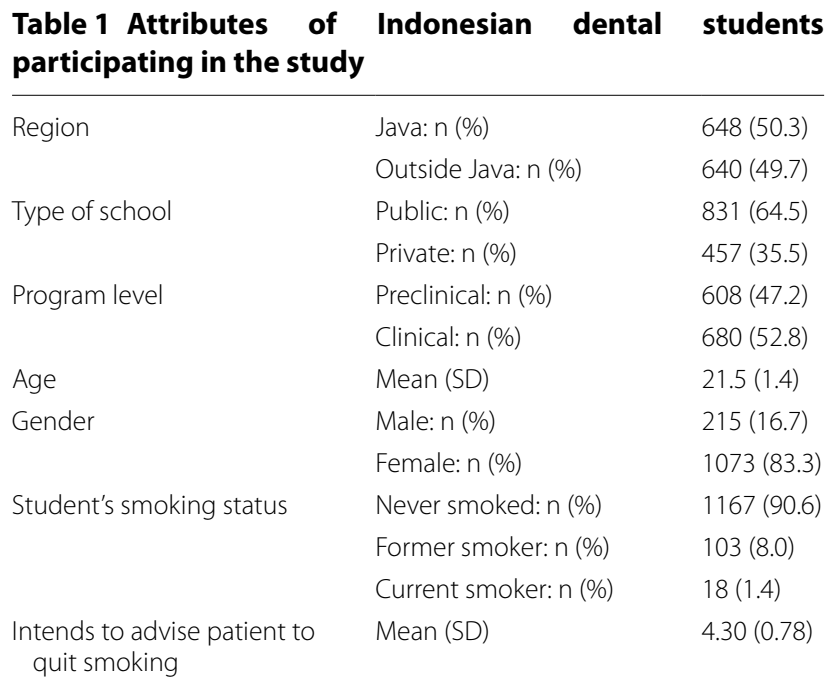

intention to advise patients to quit smoking $($ mean $=4.30$ out of 5).

Figure 1 and Table 2 show that the extent of agreement/ disagreement with various statements describing students' perspective toward TCC. The students generally disagreed (mean $=3.80$ ) that TCC is not part of dentist's role indicating a positive attitude toward TCC. They had a perspective that was more positive than negative regarding students' ability to deliver TCC including that patients would listen to students delivering TCC, that they would expect TCC from students, that assessing smoking history will not be considered intrusive, will upset patient-dentist relationship or will alienate patients (mean $>3$ out of 5). They had less positive perspective of patients' interest in quitting smoking, the possibility to provide TCC because of limited clinic time or the presence of pathway to refer patients to quit (mean $\leq 3)$.

One of the 11 items assessing perspective described the intention to give TCC and another one described attitude (considering TCC to be dentist's role). The other nine items were included in the PCA as shown in Table 3. $\mathrm{KMO}=0.83$ and $\mathrm{P}$ of Bartlett's test $<0.0001$ indicating the suitability of data to PCA. The nine items loaded on two components: students' confidence and favorable environment. Students' confidence included 5 items with loadings ranging from 0.452 to 0.708 and favorable environment included 4 items with loadings ranging from 0.514 to 0.763 . Three items loaded on both components and were included in the component where they had greater loading. The two components explained $48.8 \%$ of the variation among students' in perspective regarding TCC.

Cronbach alpha for the internal consistency of the five items representing student's confidence was 0.72 and 


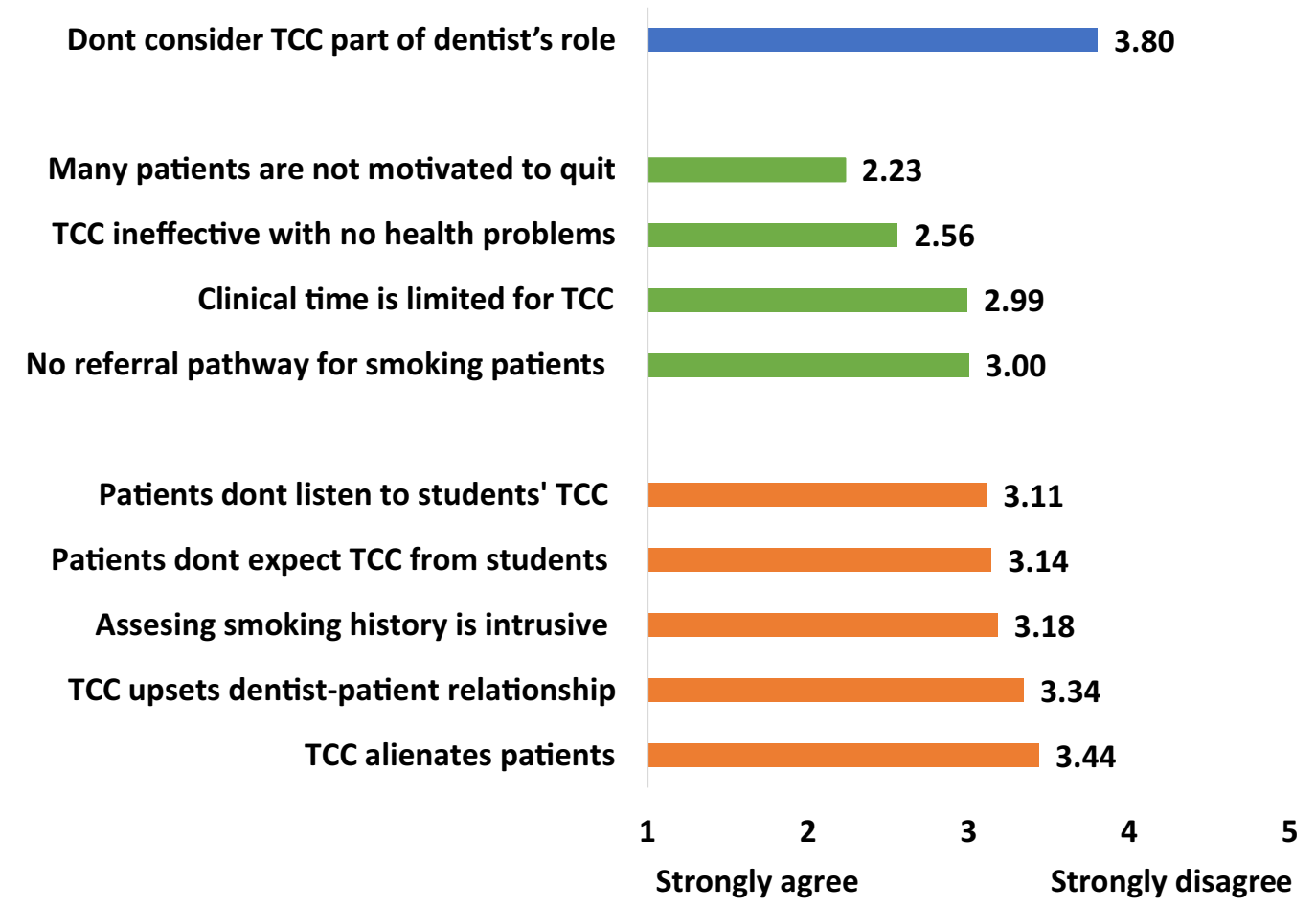

Fig. 1 Students' perspective regarding TCC

Table 2 Distribution of Indonesian dentistry students' perspective regarding TCC

\begin{tabular}{llllll}
\hline & Strongly Agree & Agree & Neutral & Disagree & Strongly Disagree \\
\hline Dont consider TCC part of the dentist's role & $23(1.8 \%)$ & $83(6.4 \%)$ & $276(21.4 \%)$ & $669(51.9 \%)$ & $237(18.4 \%)$ \\
Many patients are not motivation to quit & $290(22.5 \%)$ & $608(47.2 \%)$ & $230(17.9 \%)$ & $123(9.5 \%)$ & $37(2.9 \%)$ \\
TCC ineffective with no health problems & $203(15.8 \%)$ & $495(38.4 \%)$ & $317(24.6 \%)$ & $217(16.8 \%)$ & $56(4.3 \%)$ \\
Clinical time is limited for TCC & $94(7.3 \%)$ & $307(23.8 \%)$ & $469(36.4 \%)$ & $355(27.6 \%)$ & $63(4.9 \%)$ \\
No referral pathway for smoking patients & $72(5.6 \%)$ & $312(24.2 \%)$ & $527(40.9 \%)$ & $298(23.1 \%)$ & $79(6.1 \%)$ \\
Patients dont listen to dental students'TCC & $43(3.3 \%)$ & $260(20.2 \%)$ & $566(43.9 \%)$ & $349(27.1 \%)$ & $70(5.4 \%)$ \\
Patients dont expect TCC from students & $40(3.1 \%)$ & $256(19.9 \%)$ & $546(42.4 \%)$ & $374(29.0 \%)$ & $72(5.6 \%)$ \\
Assesing smoking history is intrusive & $25(1.9 \%)$ & $233(18.1 \%)$ & $580(45.0 \%)$ & $386(30.0 \%)$ & $64(5.0 \%)$ \\
TCC upsets dentist-patient relationship & $35(2.7 \%)$ & $243(18.9 \%)$ & $384(29.8 \%)$ & $499(38.7 \%)$ & $127(9.9 \%)$ \\
TCC alienates patients & $29(2.3 \%)$ & $184(14.3 \%)$ & $416(32.3 \%)$ & $514(39.9 \%)$ & $145(11.3 \%)$ \\
\hline
\end{tabular}

the mean (SD) $3.2(0.6)$ out of 5 indicating higher than average perception of confidence. Alpha for the internal consistency of the items representing the favorable environment was 0.65 and the mean (SD) was 2.7 (0.7) out of 5 indicating lower than average perception of favorable environment.

Table 4 shows the association between intention to provide TCC and various factors using multilevel linear regression analysis. Students in public schools expressed significantly greater intention to provide TCC $(B=01.5$, $95 \%$ CI: $0.03,0.26)$. Students who were never and former smokers were significantly more likely to express intention to provide TCC than those who were current smokers $(B=0.70,95 \% C I: 0.34,1.06$ and $B=0.60,95 \% C I$ : $0.22,0.98)$. Students who had more positive attitude that TCC is part of dentist's role were significantly more likely to express intention to provide TCC $(B=0.10$, 95\% CI: $0.05,0.15)$. Students with greater confidence in their ability to provide TCC were significantly more likely to report intending to provide TCC $(B=0.17$, 95\% CI: $0.09,0.25)$. On the other hand, students reporting greater perception of environment favorable to TCC 
Table 3 PCA of dental students' perspectives toward TCC

\begin{tabular}{lc}
\hline Items & $\begin{array}{c}\text { Student's confidence } \\
\text { environment }\end{array}$ \\
\hline I cannot determine a patient's smoking history without being intrusive & 0.452 \\
Patients do not expect TCC from a dental student & 0.659 \\
Patients do not listen to dental students during TCC & 0.681 \\
I am concerned that the message of TCC may alienate patients & 0.708 \\
Giving unwanted TCC may upset the dentist-patient relationship & 0.696 \\
Many tobacco-using patients do not have the motivation to quit & 0.358 \\
TCC is ineffective unless the patient has a related health problem & 0.514 \\
Clinical time is too limited to do counselling & 0.560 \\
There is no referral pathway for tobacco-using patients & 0.756 \\
\hline
\end{tabular}

Table 4 Multilevel analysis for factors associated
with intention to provide TCC

\begin{tabular}{lll}
\hline Factors & $\mathbf{B}(\mathbf{9 5 \%} \mathbf{C l})$ & $\boldsymbol{P}$ value \\
\hline Java versus outside Java & $0.09(-0.02,0.20)$ & 0.11 \\
Public versus private dental school & $0.15(0.03,0.26)$ & $0.01^{\mathrm{a}}$ \\
$\begin{array}{l}\text { Clinical versus preclinical program } \\
\text { level }\end{array}$ & $-0.03(-0.14,0.09)$ & 0.62 \\
Age & $-0.02(-0.06,0.02)$ & 0.36 \\
Female versus male & $-0.02(-0.14,0.10)$ & 0.78 \\
Never smoker versus current smoker & $0.70(0.34,1.06)$ & $<0.0001^{\mathrm{a}}$ \\
Former smoker versus current smoker & $0.60(0.22,0.98)$ & $0.002^{\mathrm{a}}$ \\
TCC is part of dentist's role & $0.10(0.05,0.15)$ & $<0.0001^{\mathrm{a}}$ \\
Student's confidence score & $0.17(0.09,0.25)$ & $<0.0001^{\mathrm{a}}$ \\
Favorable environment score & $-0.20(-0.27,-0.13)$ & $<0.0001^{\mathrm{a}}$ \\
\hline
\end{tabular}

$B$ : regression coefficient, $\mathrm{Cl}$ Confidence interval, ${ }^{2}$ statistically significant at

$P<0.05$, Schools included as random effect variable

were significantly less likely to report intention to provide TCC $(B=-0.20,95 \%$ CI: $-0.27,-0.13)$.

\section{Discussion}

Dental Indonesian students' intention to deliver TCC was associated with more positive attitude towards dentist's role in TCC, greater confidence in the ability to deliver TCC and less favorable supporting environment concerning patients' motivation and clinic setup. The null hypothesis of the study is, thus, rejected and the intention to deliver TCC can be explained by the constructs of the TPB.

In the present study, dental students' intention to deliver TCC was high. This high level agrees with another study in Hong Kong [28] reporting that $96 \%$ of dental students indicated that they would advise patients to stop smoking later in their careers. It was also found that $72 \%$ agreed that counseling to motivate patients to stop smoking is part of the dentist's role [28]. A systematic review [27] reported that 54 to $96 \%$ of students in several studies planned to provide TCC. In the present study, the attitude regarding dentists' role in TCC was positive. Furthermore, other studies reported that 40 to $98.1 \%$ of dental students agreed that dental professionals had a role in TCC [27].

Student's confidence was positively associated with intention to provide TCC in the present study. Adequate training increases students' confidence in their ability to help patients quit smoking and provides a structured approach that they can follow to achieve this objective. Several techniques [35] are available to enable dental professionals' to help their patients quit smoking including behavioral interventions such as the 5As intervention for patients who are ready to quit: Ask, Advise, Assess, Assist, Arrange and the 5Rs for patients who are not yet ready to quit (Relevance, Risks, Rewards, Roadblocks and Repetitions) [36]; nicotine replacement therapy (NRT), pharmacological therapy and referral to specialized centers. These methods need to be incorporated into dental curricula and continuing education activities. The study findings agree with Ching et al. [28] who reported that what most inhibited dental students from counseling patients to quit smoking was the feeling of not having sufficient skills to provide TCC.

In the present study, the intention to provide TCC was negatively associated with the presence of a favorable environment that was more strongly loaded by clinic setup factors than patient motivation factors. This may be explained by dental students' perceiving no need for their own efforts to help patients quit smoking due to the presence of a clinic setup that helps achieve this without their direct involvement. On the other hand, Pendharkar et al. [37] reported that lack of time in the clinic prevented dental students from providing interventions for patients to quit smoking. The inverse association between patient motivation and dental students' intention to provide TCC in the present study disagrees with Ching et al. [28] and a systematic review [27] reporting that patients' lack 
of motivation was a barrier against their involvement in TCC. Motivating patients to quit smoking is a skill that can be developed in dental students using proper techniques such as motivational interviewing [38, 39]. It is important that dental students learn the importance and acquire the skills for such proactive, upstream approaches to protect against the harmful oral health effects of tobacco rather than follow a reactive, downstream approach by treating tobacco effects on the hard and soft tissues of the oral cavity. In addition, these skills help integrate dental students and dentists in the healthcare team to fight the deleterious effects of tobacco on health and wellbeing.

The present study showed that dental students' intention to provide TCC was associated with the constructs of the TPB. Similarly, the TPB was previously used to explain compliance with tobacco free policy among university students [40] and predict smoking behaviors among students [41]. The advantages of using TPB for this study is that TPB provides a conceptual framework to explain behavior, which is crucial in guiding the development of training to prepare dental students to meet the needs of TCC [29]. Furthermore, TPB is characterized by several features that may help explain its widespread use as a model for the prediction and change of behavior [42]. TPB focuses directly on the determinants of behaviors, offers a clearly specified structural model, which provides a conceptual framework and theoretical constructs for analyzing determinants of the behavior under consideration [42]. The present study thus fills a knowledge gap by providing insights into the association between the TPB and intention to offer TCC among dental students in Indonesia.

In this study, students who did not smoke or were former smokers had greater intention to deliver TCC than students who were current smokers. Previous studies also stated that dentist smoking was a significant factor associated with giving TCC to patients [43-45]. Non-smoking dentists believe that dentists should help patients stop smoking, set good examples, have an influence on policy, effectively facilitate and provide treatment for smoking cessation. Conversely, dentists who smoke were reported to not record a patient's smoking history or provide counseling to stop smoking in patients $[43,44]$. Therefore, interventions are needed to help dentists who smoke quit smoking. Further results showed that students in public university expressed significantly greater intention to provide TCC. Admission into public universities is highly competitive, therefor public university students might have positive attitude, awareness [46] and literacy [47].

The large number of dental schools as well the inclusion of dental students from various dental schools are major strengths of the study. There are some limitations, however. The cross-sectional design suggests association but cannot support causality. Future longitudinal studies are needed to follow reported intention to deliver TCC over time and ascertain whether it would be associated with delivery of TCC. Some dental schools had lower response rate than others which may be attributed to the lack of onsite coordinators or their inability to collect adequate responses. The overall response rate was also low and may have introduced some selection bias affecting the representativeness of the study for Indonesian dental students. However, this low rate was previously reported for electronic surveys [48]. In addition, volunteer bias cannot be ruled out. It may suggest possible overestimation of intention to deliver TCC and underestimation of the percentage of students who were current smokers. For example, the percentage of current smokers in the present study was much lower than that of the general adult population in Indonesia recorded at 34.8\% [7] which may be partly attributed to the greater awareness of dental students than the general population and partly to under reporting.

According to the clinical practice guideline for treating tobacco use and dependence, clinicians are responsible for providing repeated interventions, documenting tobacco use status and providing brief cessation counselling [16]. It was reported that $70 \%$ of smokers see a physician, and almost one third see a dentist [16]. Therefor it is important for dental students to learn and implement evidence-based guidelines, which provides recommendations for clinical approaches in different settings. Training of dental students on tobacco cessation in dental schools is indispensable. Academic institutions play a vital role in tobacco control strategies through tobacco dependence intervention education. Dental schools are recommended to incorporate tobacco prevention and cessation intervention education into their curricula. Students can implement brief tobacco cessation counseling and can affect healthier patient outcomes [39]. As future licensed professionals, graduates will have knowledge, abilities and confidence to offer their patients brief TCC tailored to their specific health concerns and address an identified global health priority.

\section{Conclusions}

Indonesian dental students' intention to provide TCC can be explained by the constructs of the TPB. The findings have implications for dental students' training which should aim at fostering positive attitude and developing confidence in their abilities to provide TCC. In addition to the traditional focus on increasing students' knowledge, educational programs should also aim to promote soft learning outcomes. Furthermore, dental students 
who are current smokers seem to have minimal intention of helping others quit smoking. Thus, TCC for dental students themselves seems to be a priority before these students can help their patients.

\author{
Abbreviations \\ TCC: Tobacco Cessation Counseling; TPB: Theory of Planned Behavior; PCA: \\ Principal component analysis.
}

\section{Acknowledgements}

Not applicable.

\section{Authors' contributions}

DAM and FS supervised the study and contributed to the conception of the study. KVN contributed to the acquisition of data. MET contributed to the statistical analysis and data interpretation. DAM and MET revised the manuscript critically for important intellectual content and contributed to the drafting and finalizing of the manuscript. DAM acted as a liaison to obtain ethical clearance. All authors read and approved the final manuscript.

\section{Funding}

This research was supported by grants from Universitas Indonesia. Financial support included for the data collection and presentation of results.

\section{Availability of data and materials}

The raw data are available from the authors to any author who wishes to collaborate with us.

\section{Ethics approval and consent to participate}

Ethical approval was granted by the Research Ethics Committee of the Faculty of Dentistry, Universitas Indonesia. This research was conducted in full accordance with the World Medical Association Declaration of Helsinki. The principal investigator is responsible for ensuring the confidentiality of the study documents and protecting the anonymity of all respondents. Written informed consent was provided by the parents and participating adolescents assented to participating.

\section{Consent for publication}

Not applicable.

\section{Competing interests}

The authors declare that they have no competing interests.

\section{Author details}

${ }^{1}$ Department of Preventive and Public Health Dentistry, Faculty of Dentistry, Universitas Indonesia, Jalan Salemba No. 4, Jakarta 10430, Indonesia. ${ }^{2}$ Department of Pediatric Dentistry and Dental Public Health, Faculty of Dentistry, Alexandria University, Alexandria, Egypt.

Received: 16 October 2020 Accepted: 22 November 2020

Published online: 07 January 2021

\section{References}

1. Forouzanfar MH, Afshin A, Alexander LT, et al. Global, regional, and national comparative risk assessment of 79 behavioural, environmental and occupational, and metabolic risks or clusters of risks, 1990-2015: a systematic analysis for the Global Burden of Disease Study 2015. Lancet. 2016:388:1659-724

2. WHO global report on trends in prevalence of tobacco smoking 20002025. 3rd ed. World Health Organization. Geneva; 2019.

3. Reitsma MB, Fullman N, Ng M, et al. Smoking prevalence and attributable disease burden in 195 countries and territories, 1990-2015: a systematic analysis from the Global Burden of Disease Study 2015. Lancet. 2017;389:1885-906.

4. Agustina R, Dartanto T, Sitompul R, et al. Universal health coverage in Indonesia: concept, progress, and challenges. Lancet. 2019;393:75-102.
5. WHO Report on the Global Tobacco Epidemic, 2019. World Health Organization. Geneva; 2019.

6. Mbulo L, Palipudi KM, Andes L, et al. Secondhand smoke exposure at home among one billion children in 21 countries: findings from the global adult tobacco survey (GATS). Tob Control. 2016;25(e2):e95-e100.

7. World Health Organization. Regional Office for South-East Asia. 2018. WNTD: Indonesia factsheet. World Health Organization. Regional Office for South-East Asia.

8. Kaufman M, Merritt A, Rimbatmaja R, Cohen J. 'Excuse me, sir. Please don't smoke here.' A qualitative study of social enforcement of smoke-free policies in Indonesia. Health Policy Plan. 2015;30:995-1002.

9. Jacob L, Freyn M, Kalder M, Dinas K, Kostev K. Impact of tobacco smoking on the risk of developing 25 different cancers in the UK: a retrospective study of 422,010 patients followed for up to 30 years. Oncotarget. 2018;9(25):17420-9

10. Agudo A, Bonet C, Travier N, González CA, et al. Impact of cigarette smoking on cancer risk in the European prospective investigation into cancer and nutrition study. J Clin Oncol. 2016;30:4550-7.

11. Secretan B, Straif K, Baan R, et al. A review of human carcinogens--part E: tobacco, areca nut, alcohol, coal smoke, and salted fish. Lancet Oncol. 2009;10:1033-4.

12. Zhang $Y$, He J, He B, Huang R, Li M. Effect of tobacco on periodontal disease and oral cancer. Tob Induc Dis. 2019;17:40.

13. Ashkanane A, Gomez GF, Levon J, Windsor LJ, Eckert GJ, Gregory RL. Nicotine Upregulates Coaggregation of Candida albicans and Streptococcus mutans. J Prosthodont. 2019;28(7):790-6.

14. Knight ET, Liu J, Seymour GJ, Faggion JCM, Cullinan MP. Risk factors that may modify the innate and adaptive immune responses in periodontal diseases. Periodontol 2000. 2016;71(1):22-51.

15. Lallier TE, Moylan JT, Maturin E. Greater sensitivity of Oral fibroblasts to smoked vs. smokeless tobacco. J Periodontol. 2017:88(12):1-17.

16. U.S. Public Health Service. A Clinical practice guideline for treating tobacco use and dependence: 2008 update. Am J Prev Med. 2008:35:158-76.

17. Neumann A, Kumar S, Bangar S, et al. Tobacco screening and cessation efforts by dental providers: a quality measure evaluation. J Public Health Dent. 2019;79(2):93-101.

18. Brown EM, Hayes KA, Olson LT, Battles H, Ortega-Peluso C. Dentist and hygienist smoking cessation counseling and awareness of Medicaid benefit. J Public Health Dent. 2019:79(3):246-52.

19. World Health Organization. Regional Office for South-East Asia. 2012. Global adult tobacco survey: Indonesia report 2011. WHO Regional Office for South-East Asia

20. FDI / WHO. Tobacco or oral health: an advocacy guide for oral health professionals. Lowestoft: FDI world dental federation, Ferney Voltaire, France/ world dental press; 2005.

21. Carr AB, Ebbert J. Interventions for tobacco cessation in the dental setting. Cochrane Database Syst Rev. 2012;6:CD005084.

22. Zhang B, Bondy SJ, Diemert LM, Chaiton M. Can Dentists Help Patients Quit Smoking? The Role of Cessation Medications. J Can Dent Assoc. 2017;83:h1.

23. Ahmady AE, Homayoun A, Lando HA, Haghpanah F, Khoshnevisan MH. Patients' attitudes towards the role of dentists in tobacco cessation counselling after a brief and simple intervention. East Mediterr Health J. 2014:20(2):82-9.

24. Svetanoff E, Romito LM, Ford PT, Palenik CJ, Davis JM. Tobacco dependence education in U.S. dental assisting programs' curricula. J Dent Educ. 2015;79(4):378-87.

25. Nowlin JP, Lee JG, Wright WG. Implementation of recommended tobacco cessation Systems in Dental Practices: a qualitative exploration in northeastern North Carolina. J Dent Educ. 2018;82(5):475-82.

26. Prakash P, Belek MG, Grimes B, et al. Dentists' attitudes, behaviors, and barriers related to tobacco-use cessation in the dental setting. J Public Health Dent. 2013:73(2):94-102.

27. Virtue S, Waldron E, Darabos K, et al. Dental students' attitudes toward tobacco cessation in the dental setting: a systematic review. J Dent Educ. 2012;81(5):500-16.

28. Liu DCY, Ho TCY, Duangthip D, Gao SS, Lo ECM, Chu CH. Dental students' awareness, preparedness and barriers towards managing tobaccousing patients - a cross-sectional study. Int J Environ Res Public Health. 2019;16(10):1862. 
29. El Tantawi M, AlJameel AH, Fita S, AlSahan B, Alsuwaiyan F, El Meligy O. Dentists' intentions to manage drug users: role of theory of planned behaviour and continuing education. Eur J Dent Educ. 2019;23(3):364-72.

30. El Tantawi M, Gaffar B, Arheiam A, et al. Dentists' intention to report suspected violence: a cross-sectional study in eight Arab countries. BMJ Open. 2018;8(3):e019786.

31. Arheiam A, El Tantawi M, Al-Ansari A, Ingafou M, El Howati A, Gaballah K, AbdelAziz W. Arab dentists' refusal to treat HIV positive patients: a survey of recently graduated dentists from three Arab dental schools. Acta Odontol Scand. 2017;75(5):355-60.

32. Ammar N, Aly NM, Folayan MO. Behavior change due to COVID-19 among dental academics-the theory of planned behavior: stresses, worries, training, and pandemic severity. PLoS One. 2020;15(9):e0239961.

33. Ajzen I. The theory of planned behavior. Organ Behav Hum Decis Process. 1991;50:179-211.

34. Guillemin F, Bombardier C, Beaton D. Cross-cultural adaptation of health-related quality of life measures: literature review and proposed guidelines. J Clin Epidemiol. 1993;46:1417-32.

35. Pai A, Prasad S. Attempting tobacco cessation--an oral physician's perspective. Asian Pac J Cancer Prev. 2012;13(10):4973-7.

36. WHO Prevention of Noncommunicable Diseases. Toolkit for delivering the 5A's and 5R's brief tobacco interventions in primary care. World Health Organization. Geneva; 2014.

37. Pendharkar B, Levy SM, McQuistan MR, et al. Fourth-year dental students' perceived barriers to providing tobacco intervention services. J Dent Educ. 2010;74(10):1074-85.

38. Lindson N, Thompson TP, Ferrey A, Lambert JD, Aveyard P. Motivational interviewing for smoking cessation. Cochrane Database Syst Rev. 2019;7(7):CD006936.

39. Hyndman K, Thomas RE, Schira HR, Bradley J, Chachula K, Patterson SK, Compton SM. The effectiveness of tobacco dependence education in Health professional Students' practice: a systematic review and metaanalysis of randomized controlled trials. Int J Environ Res Public Health. 2019;16(21):4158
40. Record RA. Tobacco-free policy compliance behaviors among college students: a theory of planned behavior perspective. J Health Commun. 2017;22(7):562-7.

41. Karimy M, Zareban I, Araban M, Montazeri A. An extended theory of planned behavior (TPB) used to predict smoking behavior among a sample of Iranian medical students. Int J High Risk Behav Addict. 2015;4(3):e24715.

42. Ajzen I. The theory of planned behavior: frequently asked questions. Hum Behav Emerg Tech. 2020;2:314-24.

43. Lala R, Csikar J, Douglas G, Muarry J. Factors that influence delivery of tobacco cessation support in general dental practice: a narrative review. J Public Health Dent. 2017;77(1):47-53.

44. Rosseel JP, Jacobs JE, Hilberink SR, Maassen IM, Allard RHB, Plasschaert AJM, Grol RPTM. What determines the provision of smoking cessation advice and counselling by dental care teams? Br Dent J. 2009;206(7):E13.

45. John J, Thomas D, Richards D. Smoking cessation interventions in the Oxford region: changes in dentists' attitudes and reported practices 1996-2001. Br Dent J. 2003;195(5):270-5.

46. Maharani DA, Ariella S, Syafaaturrachma ID, et al. Attitude toward and awareness of medical-dental collaboration among medical and dental students in a university in Indonesia. BMC Oral Health. 2019;19(1):147.

47. Rahardjo A, Wachid MN, Adiatman M, Wimardhani YS, Maharani DA. Health literacy in dentistry among undergraduate students in Indonesia. Asian J Epidemiol. 2016;9:24-9.

48. Manfreda KL, Bosnjak M, Berzelak J, Haas I, Vehovar V. Web surveys versus other survey modes: a meta-analysis comparing response rates. Int J Market Res. 2008:50:79-104.

\section{Publisher's Note}

Springer Nature remains neutral with regard to jurisdictional claims in published maps and institutional affiliations.
Ready to submit your research? Choose BMC and benefit from:

- fast, convenient online submission

- thorough peer review by experienced researchers in your field

- rapid publication on acceptance

- support for research data, including large and complex data types

- gold Open Access which fosters wider collaboration and increased citations

- maximum visibility for your research: over $100 \mathrm{M}$ website views per year

At BMC, research is always in progress.

Learn more biomedcentral.com/submissions 